\title{
Research on Urban Branch Road System Construction under the Perspective of Eco-friendly Traffic
}

\author{
Jiajia Luo*, Linqiang Ji and Jinhe Wang \\ Building and Arts Institute of Dalian University of Technology, Dalian, Liaoning 116024, China
}

\begin{abstract}
With constant development of urbanization, urban traffic has become the most urgent problem in the contemporary metropolis. Therefore, it is an inevitable trend to positively improve the human-oriented sustainable urban eco-friendly traffic system. The urban branch road constitutes a part of urban road that will be mostly neglected while it plays a positive supportive role to the eco-friendly traffic. This article makes a contrast and analysis to the coordinated relationship between branch road network and eco-friendly traffic in same areas of Germany and Dalian City and concludes the branch road network's assurance role to the eco-friendly traffic, points out deficiency of branch road network and low density in China. The development of eco-friendly traffic, raises a series of improvement measures to the urban branch road system.
\end{abstract}

\author{
KEYWORDS \\ Urban Branch Road \\ Eco-friendly Traffic \\ Germany \\ Improvement Measures
}

\section{Introduction}

Urban traffic is closely associated with the human relationship. Almost all the people benefit from the urban traffic. With the acceleration of urbanization, swift increase of motor vehicles, congestion of traffic, followed by consumption of resources and environmental pollution, every one becomes the victim of urban traffic.

In 1994, a Canadian scholar Chris Bradshaw raised the concept of eco-friendly traffic. It aims to instruct the people to first select environment-friendly and energy-saving traffic means according to the travel distance and thus realize harmonious development between traffic and environment, traffic and resources and traffic and society. Faced with fierce traffic congestion and environmental damage, it is an inevitable trend to integrate the concept of ecofriendly traffic into the urban traffic planning.

\section{Definition of branch road}

According to 2007 version of "Planning of Urban Traffic

Copyright (c) 2015 Jiajia Luo et al.

doi: $10.18686 /$ utc.v2i1.2

Received: October 3, 2015; Accepted: October 27, 2015; Published online: December 3, 2015

This is an open-access article distributed under the terms of the Creative Commons Attribution Unported License (http://creativecommons.org/ licenses/by-nc/4.0/), which permits unrestricted use, distribution, and reproduction in any medium, provided the original work is properly cited.

${ }^{\star}$ Corresponding author: Building and Arts Institute of Dalian University of Technology, Dalian, Liaoning 116024, China. E-mail: ljj2015hy@ sunmail.cn and Road System", the branch road is called general urban road or regional road and it refers to general road in the city which plays a convergence role in the traffic and is deemed as the road which directly serves for the land use and focuses on the living service functions.

Service walking and bicycle are main functions of branch road. According to China's national codes and domestic and foreign practice, the branch road meets the bus operation requirements and constitutes an important carrier of bus service Besides, it can bear the overflow traffic responsibilities for main road and the developed branch road is a main condition to prevent node urban congestion or partial paralysis. Apart from traffic functions, the branch road bear certain functions in the living and working areas, such as commercial business by the sidewalk and collocation of office area. Urban traffic function is the essential difference between branch road and general road.

\section{Construction and eco-friendly traffic of German ur- ban branch road network}

Germany is the world's leader in eco-friendly traffic planning. With social and economic development in Germany, the traffic planning strategies have undergone reformation from private vehicle to public traffic. Currently, it has established an ecofriendly traffic system by integrating "rail transit-bicyclewalking". During this process, the branch road has provided a solid development foundation. We selected the urban center and residential area of Frankfurt and Dalian City for comparison and analyse the coordinated relationship between urban branch road network and eco-friendly traffic development [1]. 


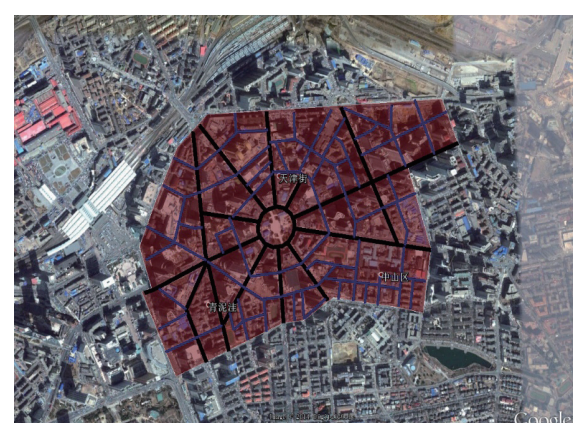

Figure 1. Road network of urban center of Dalian City.

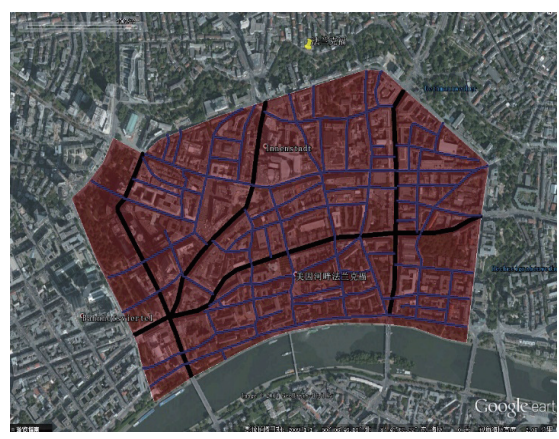

Figure 2. Road network of urban center of Frankfurt.

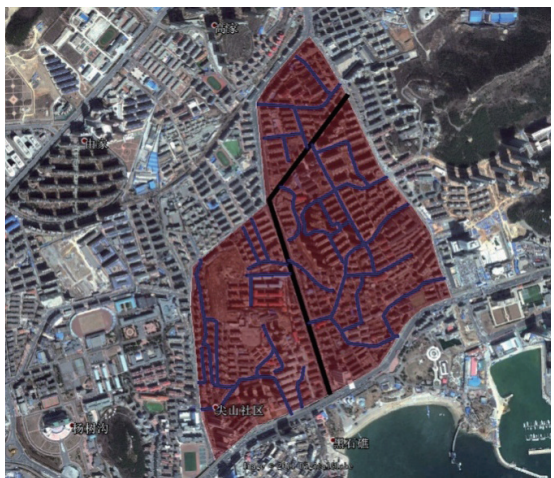

Figure 3. Road network of residential area of Dalian City.

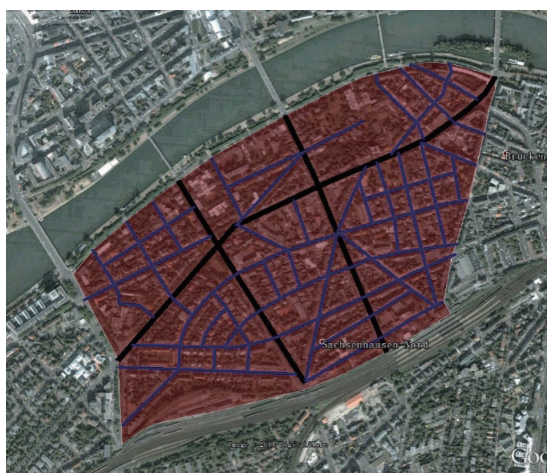

Figure 4. Road network of residential area of Frankfurt.

We can draw the following conclusion through Figure 1-4 and From Table 1.

\subsection{Density of road network}

The road in the urban center of Frankfurt is 1.3 times of that of Dalian City, the branch road is 1.7 times of that of Dalian residential area, the road in the residential area of Frankfurt is 2 times of that of Dalian residential area while branch road is 1.7 times of that of Dalian City (please refer to Table 1 in detail).

\subsection{Continuous form}

In the urban center of Dalian City, the branch road is collocated basically in the web shape. In the urban center of Frankfurt, the branch road is collocated basically in checker network but continuity requires for great improvement. In the residential area of Dalian City, the branch road is collocated in a fissure shape. It fails to establish a system or network. In the residential area of Frankfurt, the residential communities isolated by main roads are connected by "continuous branch roads". They enjoy rather good continuity.

\subsection{Width of road}

The lanes in the urban area and residential area of Dalian City are more than those in Frankfurt. However, the branch road of Frankfurt is wider than that of Dalian City. The secondary main road is collocated with electric rail in the center. Besides, afforestation belt is set up. It is also reflected in the road area rate. The road area rate in the Frankfurt urban area and residential area is much larger than that of Dalian City.

\subsection{Road design}

In the urban area and residential area of Frankfurt, the branch road section includes two-way double vehicle laneway and widened walkway, central afforestation belt is set up in some areas and almost all the branch roads are collocated with tidy parking areas by the sidewalk. In the urban area and residential area of Dalian City, the branch road section is poorly designed, walkway is rather narrow and parking is rather confused.

All in all, Frankfurt enjoys even developed branch road network. At the same time, it has a greater support to the eco-friendly traffic.

The urban area of Frankfurt is collocated with a huge amount of walking streets. Since 1968, the government has modified the branch roads in this area, prohibited vehicles, widened the walkway until 5-6 m and built up underground rails and parking buildings. In 2009, the central plaza has totally prohibited vehicles and walkway has enjoyed even complete route. Therefore, it has become the most beautiful area in Frankfurt.

In 1950s, Germany built up the peace traffic area in order to settle leftover problem of "urban traffic planning of vehicles". That is to say, the priority of city center, especially edge of walking area belongs to the pedestrians and vehicles run at the walking speed and the speed limit is $10-20 \mathrm{~km} / \mathrm{h}$. Then, it released the stipulation of " $30 \mathrm{~km}$ area" (speed limit is $30 \mathrm{~km} / \mathrm{h}$ ). The residential areas in Germany have widely adopted the measures of peace traffic 
Table 1. Branch road network parameters of domestic and foreign cities.

\begin{tabular}{|c|c|c|c|c|c|c|}
\hline & Area $/ \mathrm{km}^{2}$ & & $\begin{array}{c}\text { Total length of } \\
\text { roads } / \mathrm{km}\end{array}$ & $\begin{array}{l}\text { Road densit } \\
\left(\mathrm{km} / \mathrm{km}^{2}\right)\end{array}$ & $\begin{array}{l}\text { Average No. of } \\
\text { lanes (lane) }\end{array}$ & Road area rate \\
\hline \multirow{2}{*}{$\begin{array}{l}\text { Urban center of } \\
\text { Dalian City }\end{array}$} & \multirow{2}{*}{1.50} & Main road & 8.89 & 5.93 & 5.50 & $11.85 \%$ \\
\hline & & Branch road & 16.81 & 11.21 & 2.00 & $11.21 \%$ \\
\hline \multirow{2}{*}{$\begin{array}{c}\text { Urban center of } \\
\text { Frankfurt }\end{array}$} & \multirow{2}{*}{1.50} & Main road & 6.99 & 4.66 & 4.50 & $9.32 \%$ \\
\hline & & Branch road & 29.69 & 19.79 & 2.00 & $21.77 \%$ \\
\hline \multirow{2}{*}{$\begin{array}{l}\text { Residential area } \\
\text { of Dalian City }\end{array}$} & \multirow{2}{*}{1.10} & Main road & 1.87 & 1.70 & 6.00 & $3.40 \%$ \\
\hline & & Branch road & 12.53 & 11.39 & 2.00 & $9.94 \%$ \\
\hline \multirow{2}{*}{$\begin{array}{l}\text { Residential area } \\
\text { of Frankfurt }\end{array}$} & \multirow{2}{*}{1.10} & Main road & 5.21 & 4.74 & 4.50 & $9.47 \%$ \\
\hline & & Branch road & 21.38 & 19.43 & 2.00 & $18.50 \%$ \\
\hline
\end{tabular}

area. It means that branch roads in all the residential areas are modified into "games street" so that children can play freely. It greatly depends on the large branch road network in the residential area and microscopic planning and design of branch road $[2,3]$.

\section{Assurance role of branch road network construc- tion to eco-friendly traffic}

According to the research into German eco-friendly traffic, the branch road system is divided into three categories based on supportive role of branch road to eco-friendly traffic.

\subsection{Walkway + bicycle branch road}

We discover in the research of "general design and walking traffic of neighboring area" that walking rate is above 3 times of large-scale street are and street area without walkway among small-scale street areas and neighboring units with continuous walkway branch road. The bicycle is a eco-friendly traffic means with most similar walking speed. This branch road mainly exists in the residential area, leisure landscape area and park.

\subsection{Walking + bicycle + bus (electric rail) branch road} "Density of bus network" and "bus transfer distance" constitute important indicators to measure the adjacency of urban residents to the bus network. However, numerous cities in China fail to meet the said two indicators. It is partly because of poor bus traffic system and unreasonable bus line planning. On the other hand, it is because of poor branch road system. For instance, the urban branch road network has a small density and fails to support the bus network, the branch road has a lot of blocked roads and fails to provide smooth traffic which ultimately lead to failure of bus traffic in the daily life.

The branch road by integrating with walking, bicycle, bus and electric rail is often collocated in the area with confused functions such as urban center's commercial area. It is able to assure regional smoothness.

\subsection{Slow-speed (30-50 km/h) branch road}

The branch road mainly refers to the "traffic safety area" and " $30 \mathrm{~km}$ area" branch road. It is collocated in the residential area, edge of urban center and transitional area of urban vehicle laneway [4].

\section{Improvement measures to branch road system un- der eco-friendly traffic perspective \\ 5.1. Improvement measures of macro-level}

One of the main planning tasks for branch road network is to strike a balance between mobility and attainability:

(1) On the basis of taking reference to the codes, make a reasonable confirmation of the density of branch road network; adopt codes as compulsory articles: they enjoy reasonability and lack individuality and thus can not adapt to every city.

(2) Coordinate with the roads in the land block; the peace of large-scale residential areas and plants can not avoid damage against the rights of other road passers-by.

(3) Create favorable conditions for public traffic such as the extension of main road bus network, branch road extension depending on the collocation and scale. Under the condition of small traffic volume, two-way double laneways can assure smooth traffic of buses.

\subsection{Design measures of meso level}

The planning stage aims to determine the property of branch road. It not only concerns about the compulsory indicators, but also relates to the living quality. "Diversified and individualized" planning of branch road network focuses on the following aspects:

(1) If land use permits, increase the land area of walkway and increase social activity space for the residents.

(2) Integrate with the road plaza and park and make use of branch road collocation and afforestation to create a favorable visual effect and suitable atmosphere. Apply the space to leisure and daily exchange.

(3) Integrate with the property and traffic features of land adjacent to the street and confirm the cross section of road. The living service functions of branch road determine small-scale stores at both sides of the branch road such as restaurant and supermarket. Therefore, more non-motorized vehicles and people are produced. It is not suitable to the form of both non-motorized vehicles 
and people.

(4) Study foreign advanced experience such as " $30 \mathrm{~km}$ area" and "TOD bus community" in the branch road with both vehicles and people, make a microscopic design and slow down the speed of vehicles so that people, bicycles and vehicles can share the branch road resources.

\subsection{Design measures of micro level}

(1) Make a reasonable confirmation of width of road red line. The large city road planning stage is in accordance with "swift highway-main road-secondary main roadbranch road" grading system. A huge amount of branch roads are defined into low-level roads so that red line is narrow. In the subsequent planning, efforts are made to widen the red line, prevent excess distribution of resources to the vehicles and spare necessary resources to the walkway and afforestation environment.

(2) In the design of branch road and channeling of road, built up deceleration arch in the road, promote one-way traffic system where in some narrow sections the vehicles are requested to slow down [5].

\section{Conclusion}

We have made a contrast to the coordinated relationship of branch road network and eco-friendly traffic between German and Dalian's same areas and concluded the assurance role of branch road network to eco-friendly traffic. We also pointed out the defects of inadequate branch road network and low branch road density in Chinese cities. the development of eco-friendly traffic raised a series of improvement measures to the urban branch road system.

The completeness of urban branch road network system has a positive impact on the urban eco-friendly traffic. Currently, China's urban branch road network system suffers from serious deficiency. We have to make improvement to the branch road system at the macro-level, exosystem level and microscopic level under the eco-friendly traffic perspective in order to meet the demand for ecofriendly traffic of sustainable urban development and living quality requirements for local residents.

\section{Conflicts of interest}

These authors have no conflicts of interest to declare.

\section{Authors' contributions}

These authors contributed equally to this work.

\section{References}

1. Cai, J. (2013). Planning of Urban Road Network System. China Building Industry Press, 76-79.

2. Liu, L. L. (2013). Planning and Eco-friendly Traffic of German Urban Center: Theory, Planning and Strategy. Press of Dalian University of Technology, 11, 41-45.

3. Yang, T., \& Zhou, W. D. (2009). Branch Road Network: Crux of Construction Project of Healthy Urban Road System. Planner, 6, 11-15.

4. Liu, B. (2009). Planning and Design of China's Urban Branch Road Network. Planner, 6, 16-20.

5. Cai, J. (2005). Importance Role of Branch Road-In-depth Understanding of $<$ Planning and Design Code of Urban Road Traffic>. Urban Planning, 3, 84-88. 